\title{
Prevalence of cardiovascular disease risk factors in a rural community in West Bengal, India
}

Tanmay Nag, Arnab Ghosh

Biomedical Research Laboratory, Department of Anthropology, Visva Bharati University, Santiniketan, West Bengal, India

Address for the Correspondence: Dr. Arnab Ghosh, Biomedical Research Laboratory, Department of Anthropology, Visva Bharati University, Santiniketan - 731 235, West Bengal, India. Email: arnab_cu@rediffmail.com

\begin{tabular}{l} 
Access this article online \\
Website: www.ijmedph.org \\
DOI: 10.4103/2230-8598.165941 \\
Quick response code: \\
\hline
\end{tabular}

Background: In rural India, only a few studies have been undertaken to investigate the prevalence of cardiovascular disease (CVD). Most of the studies carried out on the urban population. Objectives: To investigate the prevalence of CVD risk factors in a rural community in West Bengal, India. Materials and Methods: A total of 1007 (645 males and 362 females) participants aged 20 years and above took part in the present study. Various anthropometric measures were undertaken using standard techniques. Metabolic profiles were measured using an auto-analyzer. Blood pressure (BP) was recorded according to standard protocol. Insulin was also measured, and homeostasis model assessment of insulin resistance was calculated accordingly. Results: The anthropometric measures are almost equal in male and female except SF4 and percentage of body fat, which are more in the female. It is observed that $52.53 \%$ population have high $\mathrm{BP}, 45.58 \%$ have high triglyceride (TG), $23.14 \%$ have high fasting blood glucose (FBG), 11.22\% have high total cholesterol (TC), and $11.62 \%$ have low high-density lipoprotein (HDL). High TC is found more in female, but high TG, high FBG, and high BP are more in male, and low HDL is found almost equal in male and female. The prevalence of three CVD risk factors clustering is also significant in male and female. Conclusion: The present study showed that prevalence of CVD risk factors is considerably high in the study population and warranted early intervention to check progressive increase of CVD risk factors in the rural folk.

Key words: Asian Indians, cardiovascular disease, diabetes, metabolic syndrome, obesity

\section{INTRODUCTION}

The prevalence of cardiovascular disease (CVD) is rising worldwide, and it accounts for 17\% of the total mortality. ${ }^{[1]}$ It is presumed that not only developed countries will be affected by CVD, the developing countries will also equally, even more, will be affected. ${ }^{[2]}$ Although the prevalence of some CVD risk factors has decreased in economically developed countries, the corresponding prevalence has increased in economically developing countries. ${ }^{[3,4]}$ It was reported ${ }^{[5]}$ that mortality from CVD was projected to decline in developed countries from 1970 to 2015, whereas it was projected to almost double in the developing countries. According to the World Health Organization (WHO), CVD will be the number one cause of morbidity and mortality in the world by the year 2015 (WHO 2000); and it is assumed that Indians would be the most affected amongst all ethnic populations. ${ }^{[4]}$ As per the report of the global burden of disease study, in the year 1990, there were 5.2 million deaths from CVD in economically developed countries and 9.1 million deaths from the same cause in developing

This is an open access article distributed under the terms of the Creative Commons AttributionNonCommercial-ShareAlike 3.0 License, which allows others to remix, tweak, and build upon the work non-commercially, as long as the author is credited and the new creations are licensed under the identical terms.

For reprints contact: reprints@medknow.com

How to cite this article: Nag T, Ghosh A. Prevalence of cardiovascular disease risk factors in a rural community in West Bengal, India. Int J Med Public Health 2015;5:259-64. 
countries. $^{\left[{ }^{6]}\right.}$ An estimated 17.3 million people died from CVDs in 2008 , representing about $30 \%$ of all global deaths. It has been predicted that by the year 2020, there will be an increase by almost $75 \%$ in global CVD prevalence, and almost all of this increase will occur in developing countries. ${ }^{[7]}$ By 2030, almost 23.6 million people will die from CVDs, mainly from heart disease and stroke.

CVD is the leading cause of death in India, ${ }^{[8]}$ and its contribution to mortality is rising; deaths due to CVD are expected to double between 1985 and 2015. ${ }^{[5,9,10]}$ According to the World Health Report of 2002, deaths due to coronary heart disease (CHD) in India rose from 1.17 million in 1991 to 1.59 million in 2000 and 2.03 million in $2010 .^{[11]}$ A total of nearly 64 million cases of CVD are likely in the year 2015, of which nearly 61 million would be CHD cases (the remaining would include stroke, rheumatic heart disease, and congenital heart diseases). Deaths from this group of diseases are likely to amount to be a staggering 3.4 million. ${ }^{[12]}$ Cardiovascular mortality in Asian Indian population is likely to climb up 103\% in men and $90 \%$ in women by $2015 .{ }^{[9]}$ It has been estimated that by 2020, CVD will be the largest cause of disability and death in India, with 2.6 million Indians predicted to die due to CVD ${ }^{[13,14]}$ It has been predicted that by the year 2020 there will be a $111 \%$ increase in cardiovascular deaths in India. It has also been predicted that India would be the heart disease capital in the world by $2020 .{ }^{[15]} \mathrm{By}$ 2020, 2.6 million Indians are predicted to die due to CHD, which constitutes $54.1 \%$ of all CVD death. ${ }^{[16,17]}$ It was shown that people with changing lifestyles due to growing urbanization are associated with adverse CVD risk factors irrespective of their habitat (rural vs. urban). ${ }^{[18]}$ Several surveys conducted across the country have shown a rising prevalence of major risk factors for CVD in urban as well as rural population. ${ }^{[19-21]}$ There are various factors involved for rapid increasing of the CVD. However, its complete etiology and mechanisms are yet to be understood.

It is seen in a survey conducted in 45 rural villages in India, 32\% of all deaths were due to CVD. On the other hand, infectious diseases were responsible for $13 \%$. It proves that the epidemic has reached its advanced stage even in rural India. ${ }^{[22]} \mathrm{CHD}$ is more prevalent in Indian urban populations, and there is a clear declining gradient in its prevalence from semi-urban to rural populations. In 2003, the prevalence of CHD in India was estimated to be 3-4\% in rural areas (two-fold higher compared with 40 years ago), and $8-10 \%$ in urban areas (six-fold higher compared with 40 years ago), with a total of 29.8 million affected (14.1 million in urban areas and 15.7 million in rural areas) according to population-based cross-sectional surveys. ${ }^{[7,23]}$ The Indian Council of Medical Research estimates that the prevalence of diabetes is $3.8 \%$ in rural areas, compared with $11.8 \%$ in urban areas. ${ }^{[24]}$ Hypertension is even more prevalent among urban (20-40\%) than rural adults (12-17\%), ${ }^{[25]}$ and was affecting an estimated 118 million inhabitants in India in 2000; this number is projected to almost double to 214 million in $2025 .{ }^{[26]}$

Therefore, it is found that the prevalence of CVD risk factors is greater in urban population of India and also increasing rapidly. There is a lack of adequate data on the prevalence of CVD risk factors in rural India. The present community-based cross-sectional study was carried out to investigate the prevalence of CVD risk factors in a rural community in West Bengal, India.

\section{MATERIALS AND METHODS}

\section{Study population}

A total of 1007 (645 males and 362 females) participants (20 years and above) took part in the study. The number of females is comparatively less as because the awareness among them is less and many of them did not want to spend time for giving personal data. The present community-based cross-sectional study was conducted in between July 2012 and February 2014. All subjects were inhabitants of Santiniketan-Bolpur area, West Bengal, India. All the participants were explained the purpose of the study and were assured to keep the information strictly confidential. Written consent was taken from each and every participant before the actual commencement of the work. Only one subject was chosen from each household to avoid intra-household clustering of CVD risk factors. The subjects are divided into five categories, namely, Group I (20-29 years, $n=79)$, Group II (30-39 years, $n=140)$, Group III (40-49 years, $n=272$ ), Group IV (50-59 years, $n=347$ ), and Group V (60 years and above, $n=169$ ) to study the prevalence of CVD risk factors according to age groups and sex. The Institutional Ethics Committee of the "Human Genetic Engineering Research Centre," Kolkata, India, had approved the study.

\section{Anthropometric measures}

Height, weight, circumferences of mid-upper arm circumference, minimum waist circumference, and maximum hip circumference as well as skinfold thickness at biceps, triceps, subscapular, and suprailiac were taken using standard techniques. ${ }^{[27]}$ Height and weight were measured to the nearest $0.1 \mathrm{~cm}$ and $0.5 \mathrm{~kg}$, respectively, with subjects wearing light clothes and without shoes. Mid-upper arm, waist, and hip circumferences were measured with an inelastic tape to the nearest $0.1 \mathrm{~cm}$, in the standing position. Waist circumference was taken at the narrowest part of the torso region as seen from the anterior aspect. Waist-hip ratio (WHR) was computed accordingly. Skinfolds thicknesses were measured on the left side of the body to the nearest $0.2 \mathrm{~mm}$ using a Holtain skinfold caliper (Holtain Corporation, UK). Sum of four skinfold thickness, that is, biceps + triceps + subscapular + suprailiac $\left(\mathrm{SF}_{4}\right)$ was calculated subsequently. Percentage of body fat (\% BF), body mass index (BMI), basal metabolic rate, and visceral fat level were measured using an Omron body fat analyzer (Omron Corporation, Tokyo, Japan). The accuracy of the body fat analyzer was checked periodically by calculating BMI manually (weight in $\mathrm{kg} /$ height in $\mathrm{m}^{2}$ ).

\section{Socioeconomic characteristics}

A schedule was used as a data collection tool. This predesigned questionnaire contained questions relating to sociodemographic information of the participants. The demographic information such as name, age, sex, marital status, etc., as well as socioeconomic 
characteristics, such as, monthly family income and expenditure, occupation and education, etc., were obtained from participants through an open-ended schedule. The information on materialistic possessions (e.g., television, washing machine, refrigerator, personal computer, air-conditioner, two wheeler, and four wheeler, etc.) and the health-related behaviors, such as, drinking status, smoking status, family history, dietary lifestyle, physical activity, and etc. ${ }^{[28]}$ were also recorded.

\section{Blood pressure}

Left arm systolic blood pressure (SBP) and diastolic blood pressure (DBP) were taken from each participant in a sitting position using a standard mercury sphygmomanometer according to a standard protocol. The $1^{\text {st }}$ and $5^{\text {th }}$ Korotkoff sounds were recorded as SBP and DBP, respectively. Two BP measurements were taken and averaged for analysis. A third measurement was taken when the difference between the two measurements was $\geq 5 \mathrm{mmHg}$, and a subsequent mean was calculated. A 5 min relaxation period between measurements was given for all participants. Mean arterial pressure (MAP) was calculated subsequently using the standard formula: $\mathrm{MAP}=\mathrm{DBP}+1 / 3(\mathrm{SBP}-\mathrm{DBP})$.

\section{Metabolic profiles}

A fasting blood sample $(7 \mathrm{ml})$ was collected from each subject for the determination of fasting blood glucose (FBG), total cholesterol (TC), triglyceride (TG), and high density lipoprotein (HDL). An overnight fast of 10-12 h was maintained before collecting blood from the participants. The plasma was separated by centrifugation at $1000 \mathrm{rpm}$ for $20 \mathrm{~min}$ at room temperature within $2 \mathrm{~h}$ of collection. TC, TG, FBG, and HDL were estimated on separated plasma using auto-analyzer. Low-density lipoprotein (LDL) and very LDL (VLDL) were then estimated using the standard formula: ${ }^{[29]} \mathrm{VLDL}=\mathrm{TG} / 5$ and $\mathrm{LDL}=\mathrm{TC}-(\mathrm{HDL}+\mathrm{VLDL})$. All metabolic variables were measured in $\mathrm{mg} / \mathrm{dl}(\mathrm{mg} \%)$ unit. Serum insulin was estimated for the subjects $(n=101)$ whose fasting glucose was got $\geq 100 \mathrm{mg} \%$. Homeostasis model assessment of insulin resistance (HOMA-IR) was then calculated by the following formula: ${ }^{[30]}$

HOMA - IR =

fasting insulin $(\mu \mathrm{U} / \mathrm{mL}) \times$ fasting glucose $(\mathrm{mg} \%)$ 22.5

\section{Statistical analyses}

Percentage of various socioeconomic characteristics, such as education, occupation, monthly income and expenditure, materialistic possession, and food habit of the population was studied. Descriptive statistics, such as mean, standard deviation (SD) and range of variables were undertaken by sex. The prevalence of CVD risk factors, such as high TC, TG, FBG, and BP, and low HDL was undertaken in respect of the age groups and sex. The prevalence of CVD risk factors clustering by sex was also compared. All statistical analyses were carried out using the SPSS Inc., Chicago, IL, USA (PC + version 14.0).

\section{RESULTS}

Percentage of socioeconomic characteristics of the study population is presented in Table 1 . It is found that $38.10 \%$ population are up to $\mathrm{X}$ standard and $29.50 \%$ are postgraduate and above. $96.60 \%$, $75.50 \%$, and $46.70 \%$ population possess television, refrigerator, and computer, respectively. $93.60 \%$ population are found nonvegetarian.

Mean, SD and range of anthropometric measures, lipid profiles, blood glucose, and BP are presented according to sex in Table 2. Mean of lipid profiles, insulin, HOMA-IR, blood glucose, and BP is not significantly different in male and female except mean of TG, which is less in female. The anthropometric measures are almost equal in male and female except $\mathrm{SF}_{4}$ and $\% \mathrm{BF}$, which are more in females.

The prevalence of CVD risk factors by age groups and sex is presented in Table 3. It is observed that $52.53 \%$ population have high BP, 45.58\% have high TG, 23.14\% have high FBG, $11.22 \%$ have high TC, and $11.62 \%$ have low HDL. High TC is found more in female, but high TG, FBG, and BP are more in male and low HDL is found almost equal in male and female.

The prevalence of three CVD risk factors clustering is shown according to sex in Figure 1. It is found that the prevalence of some clustering of three CVD risk factors is higher in men in comparison to women (high TG, FBG, and BP; high TG and BP and low HDL;

\begin{tabular}{lc} 
Table 1: Socioeconomic characteristics of the \\
study population $(\boldsymbol{n}=\mathbf{1 0 0 7 )}$ \\
\hline Variables & Percentage \\
\hline Education & \\
Up to X standard & 38.10 \\
XII Standard & 11.00 \\
Graduation & 21.40 \\
Postgraduation and above & 29.50 \\
Occupation & \\
Service & 56.50 \\
Others* & 40.90 \\
Monthly income & \\
Up to Rs. 20,000/-** & 30.60 \\
Rs. 20,001 to Rs. 40,000/- & 38.00 \\
Rs. 40,001 and above & 31.40 \\
Monthly expenditure & \\
Up to Rs. 10,000/- & 23.70 \\
Rs. 10,001 to Rs. 20,000/- & 45.70 \\
Rs. 20,001 and above & 30.60 \\
Materialistic possession & \\
Television & 96.60 \\
Washing machine & 16.90 \\
Refrigerator & 75.50 \\
Computer & 46.70 \\
Air-conditioner & 13.10 \\
Two wheeler & 70.30 \\
Four wheeler & \\
Food habit & \\
Nonvegetarian & 93.60 \\
*Farmer, housewife, labor, student, etc., ** 1 US $\$=61$ Indian rupees \\
\end{tabular}




\begin{tabular}{|c|c|c|c|c|c|c|}
\hline \multirow[t]{2}{*}{ Variables } & \multicolumn{3}{|c|}{ Male $(n=645)$} & \multicolumn{3}{|c|}{ Female $(n=362)$} \\
\hline & Mean & SD & Range & Mean & SD & Range \\
\hline Age (years) & 49.06 & 11.93 & 60.00 & 47.59 & 12.58 & 60.00 \\
\hline Height (cm) & 165.12 & 6.29 & 42.00 & 151.31 & 5.52 & 37.00 \\
\hline Weight (kg) & 66.93 & 11.59 & 73.60 & 59.81 & 11.24 & 59.80 \\
\hline MWC (cm) & 82.68 & 8.09 & 50.00 & 79.55 & 8.98 & 46.00 \\
\hline $\mathrm{MHC}(\mathrm{cm})$ & 91.74 & 7.01 & 50.00 & 94.38 & 8.89 & 49.00 \\
\hline WHR & 0.89 & 0.04 & 0.26 & 0.83 & 0.05 & 0.31 \\
\hline MUAC (cm) & 28.46 & 3.12 & 21.50 & 28.16 & 3.56 & 28.00 \\
\hline SF4 (mm) & 47.55 & 16.13 & 104.20 & 67.76 & 19.53 & 98.60 \\
\hline BMI $\left(\mathrm{kg} / \mathrm{m}^{2}\right)$ & 24.50 & 3.65 & 23.80 & 26.05 & 4.31 & 26.40 \\
\hline$\% \mathrm{BF}$ & 27.27 & 4.91 & 34.10 & 37.34 & 4.56 & 25.30 \\
\hline $\mathrm{FM}(\mathrm{kg})$ & 18.46 & 5.42 & 32.93 & 22.58 & 6.03 & 32.45 \\
\hline FFM (kg) & 48.46 & 7.58 & 52.07 & 37.22 & 6.05 & 33.85 \\
\hline BMR (kcal) & 1426.07 & 150.95 & 1083.00 & 1178.59 & 125.94 & 710.00 \\
\hline VFL & 10.92 & 4.77 & 26.00 & 9.16 & 4.56 & 29.00 \\
\hline IVF $\left(\mathrm{cm}^{2}\right)$ & 109.20 & 47.74 & 260.00 & 91.62 & 45.69 & 290.00 \\
\hline TC (mg \%) & 162.65 & 28.56 & 183.00 & 167.03 & 30.00 & 181.00 \\
\hline TG (mg \%) & 157.43 & 65.17 & 671.00 & 143.27 & 46.72 & 315.00 \\
\hline HDL (mg \%) & 45.53 & 7.51 & 41.00 & 49.04 & 6.38 & 36.00 \\
\hline LDL (mg \%) & 85.87 & 23.58 & 166.40 & 89.33 & 24.84 & 137.00 \\
\hline VLDL (mg \%) & 31.24 & 11.55 & 67.80 & 28.65 & 9.34 & 63.00 \\
\hline FBG (mg \%) & 93.39 & 30.04 & 287.00 & 91.09 & 26.12 & 232.00 \\
\hline $\mathrm{SBP}(\mathrm{mmHg})$ & 128.24 & 17.54 & 140.00 & 125.46 & 19.47 & 120.00 \\
\hline $\mathrm{DBP}(\mathrm{mmHg})$ & 82.44 & 8.33 & 70.00 & 79.41 & 8.87 & 40.00 \\
\hline MAP (mmHg) & 97.70 & 10.29 & 83.34 & 94.75 & 11.42 & 66.67 \\
\hline Insulin $(\mu \mathrm{U} / \mathrm{mL})^{*}$ & 11.79 & 6.92 & 33.05 & 14.97 & 11.30 & 54.32 \\
\hline HOMA-IR* & 63.30 & 38.90 & 183.53 & 80.85 & 63.74 & 273.78 \\
\hline
\end{tabular}

*Insulin and HOMA-IR $(n=101)$. MWC = Minimum waist circumference, $\mathrm{MHC}=$ Maximum hip circumference, $\mathrm{WHR}=$ Waist-hip ratio, $\mathrm{MUAC}=$ Mid-upper arm circumference, $\mathrm{SF}_{4}=\mathrm{Sum}$ of four skinfolds, $\mathrm{BMI}=$ Body mass index, $\% \mathrm{BF}=$ Percentage of body fat, $\mathrm{FM}=$ Fat mass, FFM $=$ Fat free mass, $\mathrm{BMR}=$ Basal metabolic rate, $\mathrm{VFL}=$ Visceral fat level, IVF = Intra-abdominal visceral fat, $\mathrm{TC}=$ Total cholesterol, TG = Triglyceride, $\mathrm{HDL}=$ High density lipoprotein, $\mathrm{LDL}=$ Low density lipoprotein, VLDL = Very low density lipoprotein, FBG = Fasting blood glucose, $\mathrm{SBP}=$ Systolic blood pressure, $\mathrm{DBP}=$ Diastolic blood pressure, $\mathrm{MAP}=$ Mean arterial pressure, $\mathrm{SD}=$ Standard deviation, HOMA-IR = Homeostasis model assessment insulin resistance

high TG and FBG and low HDL). On the other hand, the prevalence of some clustering of three CVD risk factors is found higher in women (high FBG and BP and low HDL; high TC, FBG, and BP; high TC, TG, and FBG). The prevalence of high TC, TG, and BP clustering is almost equal in men and women.

\section{DISCUSSION}

In our study, it was seen that most of the population are nonvegetarian $(93.60 \%)$ which may be a reason for the greater prevalence of CVD. It was reported earlier that nonvegetarian had a higher prevalence of CVD as compared to vegetarian. ${ }^{[31,32]}$

It was revealed from several studies that South Asians (e.g., Indians) have a more centralized distribution of body fat and markedly higher mean WHR for a given level of BMI compared with Europeans or Americans. ${ }^{[33,34]}$ It was found in our study also that population have greater waist circumference and WHRs with a greater degree of central obesity.

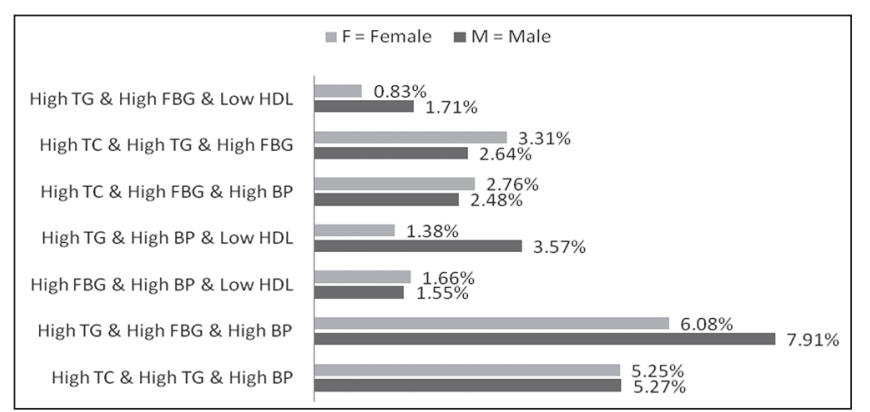

Figure 1: Clustering of at least three cardiovascular disease risk factors in a subject in the study

The prevalence of CVD risk factors, such as high TC, TG, FBG, and BP and low HDL according to age was evident in our study. It was found that the prevalence of CVD risk factors increased in male and female with age which may lead them to increasing risk of CVD. It was reported that CVD in Indian population occurs at least a decade earlier than that in Europeans and Americans. ${ }^{[35,36]}$

In our study, the prevalence of CVD risk factors was found higher in male than in the female. This finding is consistent with the previous study wherein it was reported that males are more prone to develop CVD as compared to female in rural India. ${ }^{[31]}$ The greater indulgence of males in smoking (38.4\%), taking of alcohol (17.4\%) along with stress and strain in day to day life, compared to females, may explain their greater proneness to CVD. It was reported that CVDs were more prevalent in individuals addicted to smoking and alcohol. ${ }^{[31,37-39]}$ In our study it was also observed that $40.33 \%$ females are in premenopausal stage, considering the mean age of menopause around 45 years, ${ }^{[40]}$ might also be a factor of lower prevalence (CVD risk factors) among female than male since it was already reported that CVD risk factors become prevalent after menopause. ${ }^{[40]}$ The higher prevalence of ischemic heart disease in males was also reported in other studies. ${ }^{[37,41]}$ It was reported that although the prevalence of CHD was low in the rural population of Himachal Pradesh, however, males are more prevalent than females. ${ }^{[42]}$ It was also shown that the incidence of CHD in males was 3 times higher than in females in a rural population of Kheda district, Gujarat, India. ${ }^{[43]}$

It was also observed in our study that the prevalence of CVD risk factor clustering among the population was evident. We may argue that the risk of CVD among the rural population of West Bengal, India, is high since more than one risk factor is present among many of them. This finding is consistent with the previous study wherein it was reported that CVD risk is high in the presence of one of the risk factors, presence of two doubles it and with three, the risk becomes eight-fold. ${ }^{[44]}$

It was reported in earlier studies ${ }^{[21,45,46]}$ that the prevalence of CVD risk factors is gradually increasing in the rural population of India and represents a public health concern. In the present study, it is also found that the CVD risk factors are significantly prevalent in the rural population of India. So, it seems reasonable to argue that habitat is irrespective for increasing the CVD risk factors. Since majority of the 


\begin{tabular}{|c|c|c|c|c|c|c|}
\hline \multirow{2}{*}{$\begin{array}{l}\text { Age } \\
\text { groups }\end{array}$} & \multirow[t]{2}{*}{ Sex } & \multicolumn{5}{|c|}{ Prevalence of cardiovascular disease risk factors } \\
\hline & & High TC (\%) & High TG (\%) & High FBG (\%) & High BP (\%) & Low HDL (\%) \\
\hline \multirow[t]{2}{*}{ Group I } & Male & $02(3.92)$ & $13(25.49)$ & $02(3.92)$ & $18(35.29)$ & $12(23.52)$ \\
\hline & Female & $00(0.00)$ & $08(28.57)$ & $01(3.57)$ & $03(10.71)$ & $03(10.71)$ \\
\hline \multirow[t]{2}{*}{ Group II } & Male & $08(10.96)$ & $39(53.42)$ & $18(24.66)$ & $25(34.25)$ & $07(9.59)$ \\
\hline & Female & $04(5.97)$ & $30(44.78)$ & $07(10.45)$ & $15(22.39)$ & $08(11.94)$ \\
\hline \multirow[t]{2}{*}{ Group III } & Male & $23(13.53)$ & $93(54.71)$ & $31(18.24)$ & $95(55.88)$ & $21(12.35)$ \\
\hline & Female & $17(16.67)$ & $53(51.96)$ & $21(20.59)$ & $54(52.94)$ & $15(14.71)$ \\
\hline \multirow[t]{2}{*}{ Group IV } & Male & $25(10.25)$ & $116(47.54)$ & $66(27.05)$ & $138(56.56)$ & $26(10.66)$ \\
\hline & Female & $11(10.68)$ & $38(36.89)$ & $28(27.18)$ & $53(51.46)$ & $12(11.65)$ \\
\hline \multirow[t]{2}{*}{ Group V } & Male & $10(9.35)$ & 46 (42.99) & $40(37.38)$ & $80(74.77)$ & $09(8.41)$ \\
\hline & Female & $13(20.97)$ & $23(37.10)$ & $19(30.65)$ & $48(77.42)$ & $04(6.45)$ \\
\hline \multirow[t]{2}{*}{ Total } & Male & $68(10.54)$ & 307 (47.60) & $157(24.34)$ & $356(55.19)$ & 75 (11.63) \\
\hline & Female & $45(12.43)$ & 152 (41.99) & 76 (20.99) & $173(47.79)$ & $42(11.60)$ \\
\hline Grand total & Male + female & $113(11.22)$ & $459(45.58)$ & $233(23.14)$ & $529(52.53)$ & $117(11.62)$ \\
\hline
\end{tabular}

Group I (20-29 years, $n=79, M=51, F=28)$, Group II (30-39 years, $n=140, M=73, F=67)$, Group III (40-49 years, $n=272, M=170, F=102)$, Group IV (50-59 years, $n=347$, $\mathrm{M}=244, \mathrm{~F}=103)$, Group $\mathrm{V}(60$ years and above, $\mathrm{n}=169, \mathrm{M}=107, \mathrm{~F}=62$ ).

[High TC when TC $\geq 200 \mathrm{mg} \%$; high TG when TG $\geq 150 \mathrm{mg} \%$; high FBG when FBG $\geq 100 \mathrm{mg} \%$; high BP when SBP $\geq 130$ or DBP $\geq 85 \mathrm{mmHg}$; low HDL when HDL $\leq 35$ in male and $\leq 40$ in female ${ }^{[46]}$

Indians live in rural area, CVD may lead to epidemic proportions. ${ }^{[20]}$ Hence, it is essential to find out the reasons for increasing trend of increasing prevalence of CVD risk factors among the rural population of India so that effective national health promotion and intervention program could be formulated to reduce CVD.

However, some limitations are associated with the present study, including the small sample size. Hence, it is not the representative of the entire Indian rural population. Further studies are required in other parts of the rural population of India to assess whether similar trends exist among them.

\section{Acknowledgements}

The authors are thankful to the subjects for their heartily cooperation at the time of data collection.

\section{Financial support and sponsorship}

Nil.

\section{Conflicts of interest}

There are no conflicts of interest.

\section{REFERENCES}

1. Pagidipati NJ, Gaziano TA. Estimating deaths from cardiovascular disease: A review of global methodologies of mortality measurement. Circulation 2013;127:749-56.

2. Ezzati M, Lopez AD, Rodgers A, Vander Hoorn S, Murray CJ, Comparative Risk Assessment Collaborating Group. Selected major risk factors and global and regional burden of disease. Lancet 2002;360:1347-60.

3. World Health Organization. World Health Report 2003 - Shaping the Future. Geneva, Switzerland: World Health Organization; 2003.

4. Murray JL, Lopez AD. The Global Burden of Disease: A Comprehensive Assessment of Mortality and Disability from Diseases, Injuries, and Risk Factors in 1990 and Projected to 2020. Boston, MA: The Harvard School of Public Health; 1996.

5. Reddy KS. Cardiovascular diseases in India. World Health Stat $Q$ 1993;46:101-7.
6. Murray CJ, Lopez AD. Mortality by cause for eight regions of the world: Global Burden of Disease Study. Lancet 1997;349:1269-76.

7. Gupta R. Burden of coronary heart disease in India. Indian Heart J 2005;57:632-8.

8. Mukherjee AK. India's health - Today and tomorrow. J Indian Med Assoc 1995;93:312-5.

9. Reddy KS, Yusuf S. Emerging epidemic of cardiovascular disease in developing countries. Circulation 1998;97:596-601.

10. Bulatao RA, Stephens PW. Demographic estimates and projections, by region, 1970-2015. In: Jamison DT, Mosley WH, editors. Disease Control Priorities in Developing Countries. (Health Sector Priorities Review No. 13). Washington: World Bank; 1990.

11. World Health Organization. The World Health Report 2002. Geneva, Switzerland: WHO; 2002.

12. Burden of Disease in India. New Delhi: Ministry of Health and Family Welfare, Government of India. Background Papers for the National Commission on Macroeconomics; 2005.

13. Goenka S, Prabhakaran D, Ajay VS, Reddy KS. Preventing cardiovascular disease in India - Translating evidence to action. Curr Sci 2009;97:367-77.

14. Reddy KS, Prabhakaran D, Chaturvedi V, Jeemon P, Thankappan KR, Ramakrishnan $\mathrm{L}$, et al. Methods for establishing a surveillance system for cardiovascular diseases in Indian industrial populations. Bull World Health Organ 2006;84:461-9.

15. Norman G, George C, Krishnamurthy A, Mukherjee D. Burden of cardiovascular risk factors of a rural population in South India using the WHO multivariable risk prediction algorithm. Int J Med Sci Public Health 2014;3:764-8.

16. World Health Organization. Preventing Chronic Disease: A Vital Investment. Geneva: WHO; 2005.

17. Joshi P, Idris MZ, Saran RK, Natu SM. A study of coronary heart disease and the associated risk factors in Lucknow District, India. Int J Biol Med Res 2013;4:2966-72.

18. Das M, Pal S, Ghosh A. Prevalence of cardiovascular disease risk factors by habitat: A study on adult Asian Indians in West Bengal, India. Anthropol Anz 2011;68:253-64.

19. Bhadoria AS, Kasar PK, Toppo NA, Bhadoria P, Pradhan S, Kabirpanthi V. Prevalence of hypertension and associated cardiovascular risk factors in Central India. J Family Community Med 2014;21:29-38.

20. Nag T, Ghosh A. Cardiovascular disease risk factors in Asian Indian population: A systematic review. J Cardiovasc Dis Res 2013;4:222-8.

21. Chow C, Cardona M, Raju PK, lyengar S, Sukumar A, Raju R, et al. Cardiovascular disease and risk factors among 345 adults in rural India - The Andhra Pradesh Rural Health Initiative. Int J Cardiol 2007;116:180-5.

22. Joshi R, Cardona M, lyengar S, Sukumar A, Raju CR, Raju KR, et al. Chronic diseases now a leading cause of death in rural India - Mortality 
data from the Andhra Pradesh Rural Health Initiative. Int J Epidemiol 2006;35:1522-9.

23. Gupta R. Coronary heart disease in India: Absolute numbers and economic burden. Rapid response to Ghaffar A, Reddy KS, Singhi M. Burden of noncommunicable diseases in South Asia. BMJ 2004; 328:807-10.

24. Srinath Reddy K, Shah B, Varghese C, Ramadoss A. Responding to the threat of chronic diseases in India. Lancet 2005;366:1744-9.

25. Gupta R. Trends in hypertension epidemiology in India. J Hum Hypertens 2004;18:73-8.

26. Kearney PM, Whelton M, Reynolds K, Muntner P, Whelton PK, He J. Global burden of hypertension: Analysis of worldwide data. Lancet 2005;365:217-23.

27. Lohman TG, Roche AF, Martorell R. Anthropometric Standardization References Manual. Chicago: Human Kinetics Books; 1988.

28. Ghosh A. Effects of socio-economic and behavioural characteristics in explaining central obesity - A study on adult Asian Indians in Calcutta, India. Coll Antropol 2006;30:265-71.

29. Friedewald WT, Levy RI, Fredrickson DS. Estimation of the concentration of low-density lipoprotein cholesterol in plasma, without use of the preparative ultracentrifuge. Clin Chem 1972;18:499-502.

30. Matthews DR, Hosker JP, Rudenski AS, Naylor BA, Treacher DF, Turner RC. Homeostasis model assessment: Insulin resistance and beta-cell function from fasting plasma glucose and insulin concentrations in man. Diabetologia 1985;28:412-9.

31. Agarwal AK, Yunus M, Ahmad L. An epidemiological study of cardiovascular diseases in rural community of Jawan Block, Aligarh, U.P., India. Indian J Community Med 1996;21:22-7.

32. Ghosh A. Anthropometric, metabolic and dietary fatty acids profiles in lean and obese diabetic Asian Indian subjects. Asia Pac J Clin Nutr 2006;15:189-95.

33. McKeigue PM, Shah B, Marmot MG. Relation of central obesity and insulin resistance with high diabetes prevalence and cardiovascular risk in South Asians. Lancet 1991;337:382-6.

34. Ghosh A. Comparison of anthropometric, metabolic and dietary fatty acids profiles in lean and obese dyslipidaemic Asian Indian male subjects. Eur J Clin Nutr 2007;61:412-9.
35. Ghosh A. Factor analysis of metabolic syndrome among the middle-aged Bengalee Hindu men of Calcutta, India. Diabetes Metab Res Rev 2005;21:58-64.

36. Ghosh A. Obesity measures, metabolic profiles and dietary fatty acids in lean and obese postmenopausal diabetic Asian Indian women. Anthropol Anz 2009;67:83-93.

37. Chadha SL, Radhakrishnan S, Ramachandran K, Kaul U, Gopinath N Epidemiological study of coronary heart disease in urban population of Delhi. Indian J Med Res 1990; 92:424-30.

38. Shaper AG, Pocock SJ, Walker M, Cohen NM, Wale CJ, Thomson AG. British Regional Heart Study: Cardiovascular risk factors in middle-aged men in 24 towns. Br Med J (Clin Res Ed) 1981;283:179-86.

39. Mathews JD. Alcohol use, hypertension and coronary heart disease. Clin Sci Mol Med 1968;51:661.

40. Ghosh A, Bhagat M. Anthropometric and body composition characteristics in pre- and postmenopausal Asian Indian women: Santiniketan women study. Anthropol Anz 2010;68:1-10.

41. Vakil RJ. Ischaemic heart disease in India. Br Heart J 1963;25:283-90

42. Bhardwaj R, Kandoria A, Marwah R, Vaidya P, Dhiman P, Singh B. Coronary heart disease in rural population of Himachal $-\mathrm{A}$ population based study. J Assoc Physicians India 2009;57:505-7.

43. Trivedi DH, Sharma V, Pandya H, Arya RK, Mehta R, Bansal RK, et al. Longitudinal epidemiological study of coronary heart disease in a rural population of Kheda district, Gujarat, India. Soz Praventivmed 1996;41:373-9.

44. Barna M, Biro G. Atherosclerosis: Dietary consideration. Impact of nutrition on health and disease. World Rev Nutr Diet 1989;63:126-48.

45. Gupta R, Gupta HP, Keswani P, Sharma S, Gupta VP, Gupta KD. Coronary heart disease and coronary risk factor prevalence in rural Rajasthan J Assoc Physicians India 1994;42:24-6.

46. Ghosh A, Bhagat M, Das M, Bala SK, Goswami R, Pal S. Prevalence of cardiovascular disease risk factors in people of Asian Indian origin: Age and sex variation. J Cardiovasc Dis Res 2010;1:81-5. 